\section{Improving team-sport player's physical performance with altitude training: from beliefs to scientific evidence}

\author{
Olivier Girard, ${ }^{1}$ Babette M Pluim²
}

In 1973, Sir Roger Bannister said that no clear proof of benefit of altitude training had emerged during a panel discussion on this topic, published in BJSM. ${ }^{1}$ What have we learnt in the intervening 40 years?

\section{ALTITUDE TRAINING-WHAT USE IN TEAM SPORTS?}

To date, most altitude training research is oriented towards individual endurance athletes, while the potential benefits for team sports remain largely unexplored. Hence, the safety and equality aspects of competitive football matches held above $2500 \mathrm{~m}$ have been passionately debated for over two decades. ${ }^{2}$ In 1993 this debate was invigorated when Brazil lost its first qualification game for a World championship in the stadium of $\mathrm{La} \mathrm{Paz}$ (Bolivia), located at an altitude of $\sim 3600 \mathrm{~m}$. Undoubtedly, the altered environment at altitude had a significant impact on players physical performances, ${ }^{3}$ and some athletes were better able to cope with the change in altitude than others, especially those who were better acclimated. ${ }^{4}$ Recently, the fact that Argentina suffered their worst loss in 60 years, a sound defeat of 6-1 against host Bolivia in a South Africa World Cup qualifier, clearly demonstrates that playing international games at altitude is a major challenge.

Despite the apparent lack of strong scientific evidence, it is striking to observe that altitude-training centres have been established around the globe, and are now offering team sport players the opportunity to train under sport-specific hypoxic conditions. Girard et $a l^{5}$ have shown how sprinting and small-sided games can be performed inside inflatable hypoxic marquees. Today, concepts regarding the use of hypoxic methods for team sport players are evolving. ${ }^{6}$ Owing to the widespread belief that altitude training confers a competitive advantage, this topic has an

\footnotetext{
${ }^{1}$ Research and Education Centre, ASPETAR, Qatar Orthopaedic and Sports Medicine Hospital, Doha, Qatar; ${ }^{2}$ Sports Medicine Centre Papendal, Arnhem, The Netherlands
}

Correspondence to Dr Olivier Girard, Research and Education Centre, ASPETAR, Qatar Orthopaedic and Sports Medicine Hospital, PO Box 29222, Doha, Qatar; oliv.girard@gmail.com unprecedented popularity in the team sport community.

\section{THIS ISSUE}

In this themed issue, Aspetar (Qatar Orthopaedic and Sports medicine Hospital) partners with BJSM to provide the journal's readership with a representation of the current research into altitude training and team sports. As the chair of the scientific committee of the Altitude Training and Team Sports Conference, I am proud to be guest editing this issue, in which we present current updates and original investigations authored by international experts in this bourgeoning field.

\section{Current updates}

The current updates section starts with a comprehensive summary of the factors that affect either sprint performance or the ability to recover from maximal or near-maximal efforts at sea level, and discusses the evidence that these may be improved by altitude training. ${ }^{7}$ Billaut and Aughey ${ }^{8}$ then illustrate the adverse effects of acute altitude exposure on single-sprint and repeated-sprint capacity. The authors conclude that players displaying enhanced muscle reoxygenation capacity, greater buffering power and maintained cerebral oxygenation should better cope with the stress of altitude.

Changes in haemoglobin mass reflect major systemic adaptations. Saunders et $a l^{9}$ postulate that an $\sim 1 \%$ increase in haemoglobin mass results in a $0.6-0.7 \%$ increase in maximal oxygen uptake in most elite endurance athletes after various forms of altitude training. Gore et al ${ }^{10}$ present a meta-analysis (17 studies) of papers having used the carbon monoxide rebreathing technique to determine haemoglobin mass. A key feature of their review is their demonstration that classical altitude training camps as short as 2 weeks are likely to increase haemoglobin mass and benefit most athletes.

Chapman ${ }^{11}$ explains the importance of screening arterial oxyhaemoglobin saturation and hypoxic ventilatory responses in order to determine how team members might individually respond to hypoxic conditions. Readers are provided with overwhelming evidence promoting the individualisation of adjustments in exercise intensity and/or duration at altitude. Faiss $e t a l^{12}$ critically analyse the results of studies involving high-intensity exercise performed in hypoxia for sea-level performance enhancements, by differentiating intermittent hypoxic training and repeated sprint training in hypoxia.

\section{Original investigations}

The first set of original investigations deals with the various aspects of altitude exposure in three different team sports. First, McLean et al ${ }^{13}$ show that two consecutive preseason moderate altitude camps yield a similar (4\%) increase in haemoglobin mass in elite Australian footballers, while they do not change their haemoglobin mass consistently from year to year. Buchheit et al ${ }^{14}$ demonstrate that, compared with training in the heat-only, an additional hypoxic stimulus during sleep and particular training sessions has no high-intensity running performance benefit, immediately after a 14-day offseason camp in professional Australia football players. In a group of rugby players, Harvey et $a l^{15}$ report that 12 repeated-sprint training sessions in hypoxia resulted in a twofold greater improvements in the capacity to perform repeated high-intensity aerobic work than equivalent normoxic training. Finally, Garvican-Lewis et al ${ }^{16}$ highlight that 10 days of simulated 'living high-training low' altitude training increases oxygen transport capacity in elite female water polo players by $3-4 \%$, which is strongly related to specific aerobic fitness.

In the final set of papers of the supplement, ${ }^{17-21}$ the International Study on Football at Altitude $3600 \mathrm{~m}$ (IFA3600) is presented with the intention of documenting, first, the extent to which running performance is altered at $3600 \mathrm{~m}$ as compared with sea-level and, second, the time-course of acclimatisation of both physical performance and the underlying physiological adaptations associated with training and playing at $3600 \mathrm{~m}$ (sea-level native players) and at low altitude (high altitude-adapted players). Specifically, of a series of seven companion papers attempting to quantify the acute and chronic effects of competing at La Paz, Bolivia $(3600 \mathrm{~m})$ on game and training running performance, acclimatisation, haematology and sleeping patterns of national-level junior players, five are published in this supplement. The two remaining papers can be found in a regular issue of BJSM. ${ }^{21} 22$

Finally, the culminating point of this supplement is perhaps the position statement 
featuring scientifically based strategies that may be of importance to consider when intending to implement altitude training with team sport players. $^{23}$

\section{WHAT ARE THE NEW FINDINGS?}

Forty years after the publication of the initial altitude training issue in this journal, ${ }^{1}$ major advances have been made from a performance and mechanistic perspective.

The three main points are

1. The current level of evidence for the efficacy of hypoxic methods to improve exercise performance at moderate or high altitude (acclimatisation) is well established. However, the benefits of using a 'living high-training low', 'Living high-training high' and 'living low-training high' altitudetraining intervention or a combination of those methods to improve team sport-related physical performance on return to sea level are not as definitive.

2. Training camps as short as 2 weeks can increase haemoglobin mass substantially in a range of professional team sport players, while limited data currently exists regarding the time course of non-haematological adaptations.

3. It is undeniable that no single recommendation is likely suitable for all players in a team, or across all team sports, requiring the development of optimised interventions at the individual player level.

Finally, the physiology underlying altitude-related effects on physical performance in many team sports is still far from fully understood.

Contributors OG was involved in the writing of the manuscript. BMP was involved in the review and approval of the manuscript.

Competing interests None.

Provenance and peer review Not commissioned; externally peer reviewed.

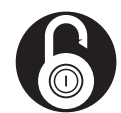

\section{OPEN ACCESS}

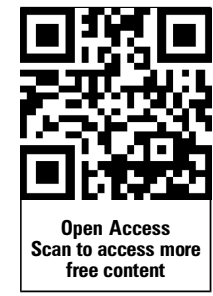

Open Access This is an Open Access article distributed in accordance with the Creative Commons Attribution Non Commercial (CC BY-NC 3.0) license, which permits others to distribute, remix, adapt, build upon this work non-commercially, and license their derivative works on different terms, provided the original work is properly cited and the use is noncommercial. See: http://creativecommons.org/licenses/ by-nc/3.0/

To cite Girard 0, Pluim BM. Br J Sports Med 2013;47:i2-i3.

Accepted 9 October 2013

Br J Sports Med 2013;47:i2-i3.

doi:10.1136/bjsports-2013-093119

\section{REFERENCES}

1 Bannister R, Raymond Owen J, Keul J, et al. Chairman's opening remarks. Br J Sports Med 1974;8:3-4.

2 McSharry PE. Altitude and athletic performance: statistical analysis using football results. $B M J$ 2007;335:1278-81.

3 Nassis GP. Effects of altitude on football performance: analysis of the 2010 FIFA Wold Cup Data. J Strength Cond Res 2013;27: 703-7.

4 Gore CJ, McSharry PE, Hewitt AJ, et al. Preparation for football competition at moderate to high altitude. Scand J Med Sci Sports 2008;18:85-95.

5 Girard O, Brocherie F, Millet G. On the use of mobile inflatable hypoxic marquees for sport-specific altitude training in team sports. Br J Sports Med 2013;47: i121-3.

6 Millet GP, Brocherie F, Faiss R, et al. Hypoxic training and team sports: a challenge to traditional methods. Br J Sports Med 2013;47:i6-7.

7 Bishop DJ, Girard O. Determinants of team-sport performance: implications for altitude training by team-sport athletes. Br J Sports Med 2013;47: i17-23.

8 Billaut F, Aughey R. Update in the understanding of altitude-induced limitations to performance in team-sport athletes. Br J Sports Med 2013:47: i22-5.
9 Saunders P, Garvican-Lewis L, Schmidt W, et al. Relationship between changes in hemoglobin mass and maximal oxygen uptake after hypoxic exposure. Br J Sports Med 2013;47:i26-30.

10 Gore C, Sharpe K, Garvican-Lewis L, et al. Altitude training and haemoglobin mass from the optimised carbon monoxide re-breathing method determined by a meta-analysis. Br J Sports Med 2013;47:i31-9.

11 Chapman $R$. The individual response to training and competition at altitude. Br J Sports Med 2013;47: i40-4.

12 Faiss R, Girard O, Millet GP. Advancing hypoxic training in team sports: from intermittent hypoxic training to repeated sprint training in hypoxia? $\mathrm{Br} J$ Sports Med 2013;47:i45-50.

13 McLean BD, Buttifant D, Gore CJ, et al. Year-to-year variability in haemoglobin mass response to two altitude training camps. Br J Sports Med 2013;47: i51-8.

14 Buchheit M, Racinais S, Bilsborough J, et al. Adding heat to the live-high train-low altitude model: a practical insight from professional football. $\mathrm{Br} J$ Sports Med 2013;47:i59-69.

15 Harvey G, Cooke K, Sumners D, et al. Repeated sprint training in normobaric hypoxia. Br J Sports Med 2013;47:i74-9.

16 Garvican-Lewis L, Wachsmuth N, Kley M, et al. Changes in blood gas transport of altitude native soccer players near sea-level and sea-level native soccer players at altitude (ISA3600). Br J Sports Med 2013;47:193-9.

17 Gore CJ, Aughey R, Bourdon P, et al. Methods of the International study on Soccer at Altitude 3600 m (ISA3600). Br J Sports Med 2013:47:i80-5.

18 Sargent C, Schmidt W, Aughey R, et al. The impact of altitude on the sleep of young elite soccer players (ISA3600). Br J Sports Med 2013;47:i86-92.

19 Buchheit M, Simpson B, Garvican-Lewis L, et al. Wellness, fatigue and physical performance acclimatisation to a 2-week soccer camp at $3600 \mathrm{~m}$ (ISA3600). Br J Sports Med 2013;47:i100-6.

20 Aughey R, Hammond K, Varley M, et al. Soccer activity profile of altitude versus sea-level natives during acclimatisation to $3600 \mathrm{~m}$ (ISA3600). Br J Sports Med 2013:47:i107-113.

21 Buchheit M, Simpson B, Schmidt W, et al. Predicting sickness during a 2-week soccer camp at 3600 m (ISA3600). Br J Sports Med 2013;47:1124-7.

22 Roach GD, Schmidt WF, Aughey RJ, et al. The sleep of elite athletes at sea level and high altitude: a comparison of sea-level natives and high-altitude natives (ISA3600). Br J Sports Med 2013;47: i114-120.

23 Girard 0, Amann M, Aughey R, et al. Position statement-Altitude training for improving teamsport players performance: current knowledge and unresolved issues. Br J Sports Med 2013;47:18-16. 